\title{
Mapping of QTL Associated With Heat Tolerance At The Reproductive Stage In Rice(Oryza Sativa L.)
}

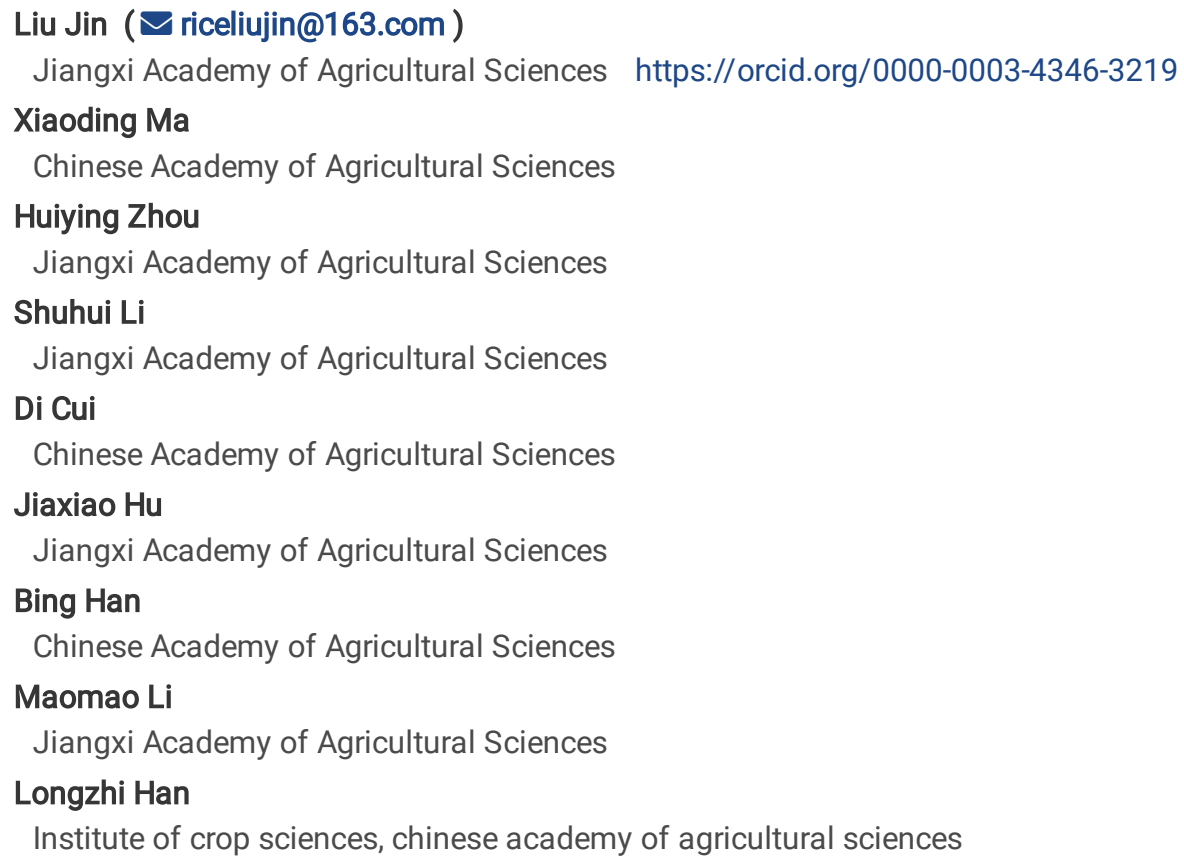

\section{Research Article}

Keywords: Rice, Heat tolerance, Spikelet fertility, QTL mapping, BSA

Posted Date: September 17th, 2021

DOI: https://doi.org/10.21203/rs.3.rs-813354/v1

License: (c) (i) This work is licensed under a Creative Commons Attribution 4.0 International License. Read Full License 


\section{Abstract}

Climate change has a negative effect on rice production and food security. High temperature stress is a major obstacle and can significantly reduce yield. A set of recombinant inbred lines (RILs) derived from the cross between Longdao5 (heat-sensitive) and Zhongyouzao8 (heattolerant) was used in the identification of heat tolerant QTL. Spikelet fertility (SF) and heat tolerance (HT) indexes showed a significant difference among the parents and RILs population, and SF and HT have different of effect under natural and artificial high temperature conditions. Sixty-one QTLs were detected on chromosomes 1-8, 10 and 12, while 25, 27 and 14 additive QTLs were identified under the control, natural and artificial high temperature conditions, respectively. Pleiotropic effects and QTL hotspots are the key factors affecting these traits, three key major QTL clusters qHTSF1, qHTSF4, and QHTSF12 can be stably expressed. In addition, epistatic effect is an important component in the regulation of heat tolerance. A total of 17 pairs of epistatic interaction loci were detected, and these additive QTL clusters have a significant epistatic effect. Bulk segregant analysis (BSA) method was proved to be a convenient method to detect major QTLs. Three QTLs, namely $q S F 1, q S F 2$ and $q S F 12$ were detected under high temperature environment, and there is a highly significant correlation among these addictive QTLs. These results will lay the foundation for the further fine mapping of these major QTLs and enrich the molecular marker-assisted selection of heat-tolerant gene resources in rice breeding.

\section{Introduction}

Due to the global warming caused by greenhouse gases the global average surface temperature has increased by $0.85^{\circ} \mathrm{C}$ over the past century, which has a huge effect on sustainable agricultural development (Teixeira et al. 2013; Lawas et al. 2019). Heat stress is defined as the rise in temperature beyond a critical threshold for a period of time sufficient to cause irreversible damage to plant growth and development (Wahid et al., 2007; Cheabu et al., 2019). Extremely high temperature leads to severe crop yield losses and reduced milling quality, which is predicted to cause food crises and result in widespread risk of food insecurity and social problems in the future (Mba et al. 2012; Zhang et al., 2014).

Rice (Oryza sativa L.) is one of the most important grain crops in the world, and it i a stable food source for more than half of the world's population (Wang et al. 2014). Rice is highly susceptible to heat stress, and spikelet fertility and grain filling often go through serious damage under high-temperature stress, leading to significant yield losses (Ye et al., 2015). High temperature of over $35^{\circ} \mathrm{C}$ at the flowering stage reduces pollen viability and spikelet sterility in rice, which can lead to a significant decrease of the yield, quality, and harvest indexes (Matsui et al. 2001; Wang et al., 2019). Rice yield losses due to high temperature have been reported in many countries across continents (Mba et al., 2012; Trnka et al., 2014). Through climate modeling analysis, an increase in global mean temperature and a higher frequency of intense heat spikes have been predicted, and then $16 \%$ of rice growing areas will be continuously subjected to five days of heat stress during the reproductive stage in the coming decades (Jagadish et al. 2015; Huang et al. 2017). Reducing the occurrence of heat-related damages, such as rice chalkiness and spikelet sterility, is the major goal in global rice production under climate change. Breeding approaches for improving heat tolerance and developing new heat-tolerant rice varieties are of essential and critical importance to the sustenance of rice production in future global warming (Huang et al., 2017; Karwa et al., 2020).

Climate change-driven heat stress during the reproductive stage of the crop affects spikelet fertility and yield. Heat tolerance during the heading and flowering stage is a quantitative trait controlled by multiple QTLs, and eight QTLs for spikelet fertility under high temperature conditions were identified (Jagadish et al., 2010; Zhao et al., 2016). Ye et al (2015) identified 8 QTLs controlling spikelet fertility under high temperature, while the stable major QTL qHTSF4. 1 was an important source for enhancing heat tolerance. Cloning and fine mapping major QTL responses to high temperature stress will help breeders produce rice varieties adapted to future climates, and enhancing heat tolerance is one of the most hot-spot method for molecular and breeding biology (Jagadish et al., 2010). Several QTLs associated with heat stress tolerance have been reported in rice. However, several major QTLs have been fine-mapped and cloned, while the molecular genetic mechanisms of spikelet fertility and yield under different high temperatures have not been comprehensively studied. This study dissected the genetic basis and identified novel QTLs of heat tolerance in a set of RIL populations derived from a cross between the heat-sensitive Longdao5 and the heat-tolerant Zhongyouza08. QTL analyses were performed under the control, natural and artificial high temperature environments at the heading and flowering stage in two years. The research goal of QTL comparison analysis is to identify the stable QTL expression which affects important heat tolerant traits under different high temperature stress, and to provide the basis for future fine mapping and molecular breeding of rice.

\section{Materials And Methods}

\section{Plant materials and field trials}


A set of RILs $\left(\mathrm{F}_{8}\right)$ populations consisting of 187 lines were developed from a cross between Longdao5 (LD5, japonica) and Zhongyouzao8 (ZYZ8, indica) by the single seed descent method. In particular, ZYZ8 was a heat-tolerant and high-yielding cultivar, and LD5 was a heatsensitive cultivar. The RILs along with the parents were evaluated under natural field and artificial greenhouse conditions. At all locations, plants were sown in seedling nurseries, and 25-day-old seedlings were transplanted into paddies. Each line was planted in three rows of 8 hills, spaced at $16.5 \mathrm{~cm} \times 20 \mathrm{~cm}$, with one seedling per hill. The fifield management (including irrigation, fertilizer application and pest contro) was conducted according to the normal procedures for rice

Two staggered sowings were made during the middle season of 2019 and 2020, with the first sowing timed to coincide the normal growing season and then the second sowing to coincide with the natural and artificial heat stress during the heading and flowering stage. The first sown set did not experience any stress, namely control environment, while the second set experienced the heat stress, natural and artificial high temperature environments. The parents and RILs populations used in this experiment were provided with adequate exposure to different temperature treatments during the heading and flowering period (Table 1).

Table 1

The temperature recorded from different temperature treatments during heading and flowering stage

\begin{tabular}{|c|c|c|c|c|c|c|c|}
\hline \multirow[t]{2}{*}{ Years } & \multirow[t]{2}{*}{ Treatments } & \multicolumn{2}{|c|}{ Maximum temperature $\left({ }^{\circ} \mathrm{C}\right)$} & \multicolumn{2}{|c|}{ Minimum temperature $\left({ }^{\circ} \mathrm{C}\right)$} & \multicolumn{2}{|c|}{ Daily average temperature $\left({ }^{\circ} \mathrm{C}\right)$} \\
\hline & & Range & Mean & Range & Mean & Range & Mean \\
\hline \multirow[t]{3}{*}{2019} & $\mathrm{E} 1$ & $25.0-36.0$ & 32.4 & $20.0-29.0$ & 24.3 & $23.0-32.5$ & 28.3 \\
\hline & E2 & $34.0-38.0$ & 36.2 & $27.0-29.0$ & 28.3 & $30.0-34.5$ & 32.5 \\
\hline & E3 & $40.5-46.0$ & 43.2 & $26.5-30.0$ & 28.5 & $34.0-36.5$ & 34.8 \\
\hline \multirow[t]{3}{*}{2020} & $\mathrm{E} 4$ & $21.0-34.0$ & 27.0 & $18.0-26.0$ & 21.4 & $19.5-30.0$ & 24.2 \\
\hline & E5 & $35.0-39.0$ & 37.5 & $26.0-30.0$ & 27.9 & $31.0-35.0$ & 32.7 \\
\hline & E6 & $38.1-44.0$ & 41.0 & $27.0-31.0$ & 28.5 & $33.2-36.3$ & 34.5 \\
\hline
\end{tabular}

\section{Phenotypic evaluation}

The local weather forecast was used to select sunny periods of at least 5 days suitable for the high temperature treatment. Two days before the high temperature treatment, ten uniform plants that were predicted to undergo heading during the treatment were selected per line in the afternoon. Five panicles per plant were selected and marked with a fiber rope. When each plant started heading, six plants were left in the field as controls, three plants was transferred into artificial greenhouse, two replicate pots. After 6 days of high temperature treatment, the plants were moved back to the natural conditions until seeds matured.

For estimating spikelet fertility, seeds from the five marked panicles in each plant were sampled. Spikelet fertility was calculated as the ratio of filled spikelets to total number of spikelets per panicle and expressed as percentage. The observations averaged over three plants were used for statistical analyses and evaluation of the heat tolerance of the lines. Meanwhile, HT index was calculated for spikelet fertility to assess the relative performance of RILs under heat stress through the following formula.

HT = Spikelet fertility under heat stress /Spikelet fertility in control condition, HT range 0-1.

\section{DNA extraction and linkage map construction}

Genomic DNA was extracted from fresh frozen leaves according to the CTAB method. Polymerase chain reaction (PCR) reaction mixture (10 $\mu \mathrm{L}$ ) contained $1.5 \mu \mathrm{L} 20 \mathrm{ng} / \mu \mathrm{L}$ genomic DNA, $1.0 \mu \mathrm{L}$ each primer, $1.5 \mu \mathrm{L}$ 10. PCR buffer, $2.0 \mu \mathrm{L} 2.5 \mathrm{mmol} / \mathrm{L} \mathrm{dNTP}, 0.2 \mu \mathrm{L} 5 \mathrm{U} / \mu \mathrm{L}$ Taq DNA

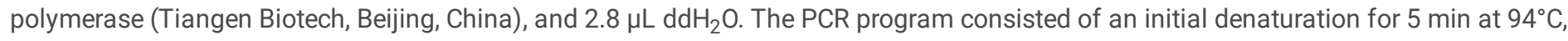
followed by 35 cycles of $94^{\circ} \mathrm{C}$ denaturation for $45 \mathrm{~s}, 55-60^{\circ} \mathrm{C}$ annealing for $45 \mathrm{~s}$, and $72^{\circ} \mathrm{C}$ extension for $45 \mathrm{~s}$, with a final extension at $72^{\circ} \mathrm{C}$ for 10 min and then the products holding at $12^{\circ} \mathrm{C}$. PCR products were separated by electrophoresis on $4 \%-5 \%$ agarose gels, mixed with 0.1 $\mathrm{mg} / \mathrm{ml}$ of ethidium bromide, and the results were observed and recorded using a gel imaging system. A total of 762 SSR, Indel and ILP primer pairs were used to survey the polymorphism between the two parents. Evenly distributed on chromosomes 1-12 of polymorphic 223 SSR, Indel and ILP markers were selected for polymorphism survey between the parents, to construct a genetic map for the RIL population. The genetic map was $1,514 \mathrm{cM}$ in length, with an average of 18.58 markers per chromosome and an average distance of $6.79 \mathrm{cM}$ between adjacent markers. 


\section{QTL analysis and bulked segregant analysis}

Additive effect QTL analysis was performed based on inclusive composite interval mapping implemented with the QTL IciMapping4.2 program (Wang et al. 2019). In additive effect QTLs analysis, the walking speed along chromosomes was $1.0 \mathrm{cM}$, when their logarithm of odds (LOD) scores exceeded 2.50 (when QTLs were detected in more than two environments LOD $\geq 2.40$ ). The relative contribution of a genetic component was calculated as the PVE (\%) and additive effect in the selected model. The QTLs were named according to the guidelines described by McCouch (2008).

In the initial approach to run a bulked segregant analysis (BSA), only those markers which were polymorphic between the parents were utilized. To construct the bulks, ten genotypes ( $5 \%$ of RILs) that were found to show extreme phenotypes for SF and HT were selected to construct two DNA pools, one for heat tolerant and the other for heat sensitive. The polymorphic SSR markers were then surveyed over the bulks and the parents.

\section{Results}

\section{Phenotypic variation in the RIL population}

Grain number (GN), setting grain number (SN) and SF showed a significant difference among the parents (Table 1). There is a significant difference of heat tolerance index(HT) between LD5 and ZYZ8 under high temperature environments. GN, SN, SF and HT of the RILs varied exhibited an approximate continuous normal distribution under different conditions. Meanwhile, the transgressive segregation that fell beyond the parents was observed, suggesting that the set of RILs was suitable for QTL analysis (Table 2, Fig. 1). In addition, natural and artificial high temperature have different degrees of effect on SF and HT. The latter has strong heat stress, and then the heat tolerance mechanism from different treatments maybe different. 
Table 2

Heat tolerance-related traits from the parents and RILs populations

\begin{tabular}{|c|c|c|c|c|c|c|c|c|}
\hline \multirow[t]{2}{*}{ Year } & \multirow[t]{2}{*}{ Treatments } & \multirow[t]{2}{*}{ Trait } & \multicolumn{2}{|l|}{ Parents } & \multicolumn{4}{|c|}{ RILs populations } \\
\hline & & & LD5 & ZYZ & Mean \pm Sd & Range & Skewness & Kurtosis \\
\hline \multirow[t]{9}{*}{2019} & Control & $\mathrm{GN}$ & $78.40 \pm 5.60$ & $\begin{array}{l}256.20 \pm \\
15.60 \star \star\end{array}$ & $\begin{array}{l}143.29 \pm \\
44.80\end{array}$ & $\begin{array}{l}50.80- \\
290.20\end{array}$ & 0.58 & 0.65 \\
\hline & & $\mathrm{SN}$ & $65.40 \pm 4.00$ & $\begin{array}{l}166.22 \pm \\
10.34^{\star \star}\end{array}$ & $\begin{array}{l}85.54 \pm \\
34.38\end{array}$ & $\begin{array}{l}24.80- \\
223.20\end{array}$ & 0.58 & 0.65 \\
\hline & & SF & $83.42 \pm 5.65$ & $\begin{array}{l}64.88 \pm \\
10.45^{\star \star}\end{array}$ & $\begin{array}{l}60.22 \pm \\
16.71\end{array}$ & $\begin{array}{l}36.50- \\
100.00\end{array}$ & -0.47 & 0.05 \\
\hline & $\begin{array}{l}\text { Nature high } \\
\text { temperature }\end{array}$ & SN & $50.40 \pm 5.65$ & $\begin{array}{l}127.07 \pm \\
10.32^{\star \star}\end{array}$ & $\begin{array}{l}111.83 \pm \\
34.81\end{array}$ & $\begin{array}{l}28.60- \\
218.00\end{array}$ & 0.42 & 0.03 \\
\hline & & SF & $63.47 \pm 6.40$ & $58.47 \pm 12.30 *$ & $\begin{array}{l}70.59 \pm \\
14.91\end{array}$ & $\begin{array}{l}27.68- \\
96.32\end{array}$ & -0.52 & -0.37 \\
\hline & $\begin{array}{l}\text { Artificial high } \\
\text { temperature }\end{array}$ & $\mathrm{SN}$ & $24.25 \pm 5.20$ & $54.14 \pm 8.30^{\star *}$ & $\begin{array}{l}35.11 \pm \\
16.85\end{array}$ & $4.53-86.54$ & 0.42 & 0.19 \\
\hline & & SF & $26.23 \pm 5.00$ & $31.24 \pm 10.20 *$ & $\begin{array}{l}28.44 \pm \\
12.66\end{array}$ & $1.44-65.05$ & 0.32 & -0.04 \\
\hline & & HTN & $0.76 \pm 0.09$ & $0.90 \pm 0.07 *$ & $0.36 \pm 0.39$ & $0.08-0.87$ & -0.40 & 1.24 \\
\hline & & HTA & $0.31 \pm 0.06$ & $0.48 \pm 0.04^{*}$ & $0.52 \pm 0.20$ & $0.03-0.91$ & -0.29 & -0.70 \\
\hline \multirow[t]{9}{*}{2020} & Control & GN & $\begin{array}{l}112.40 \pm \\
10.20\end{array}$ & $\begin{array}{l}211.00 \pm \\
20.50 * \star\end{array}$ & $\begin{array}{l}160.74 \pm \\
45.20\end{array}$ & $\begin{array}{l}82.20- \\
284.20\end{array}$ & 0.45 & -0.18 \\
\hline & & $\mathrm{SN}$ & $88.80 \pm 8.50$ & $\begin{array}{l}146.10 \pm \\
15.00 * \star\end{array}$ & $\begin{array}{l}111.83 \pm \\
34.81\end{array}$ & $\begin{array}{l}28.60- \\
218.00\end{array}$ & 0.42 & 0.03 \\
\hline & & SF & $79.00 \pm 8.20$ & $\begin{array}{l}69.24 \pm \\
10.25^{\star \star}\end{array}$ & $\begin{array}{l}74.10 \pm \\
11.75\end{array}$ & $\begin{array}{l}34.78- \\
96.32\end{array}$ & -0.44 & -0.12 \\
\hline & $\begin{array}{l}\text { Nature high } \\
\text { temperature }\end{array}$ & SN & $\begin{array}{l}71.81 \pm \\
12.00\end{array}$ & $\begin{array}{l}101.67 \pm \\
15.00 * \star\end{array}$ & $\begin{array}{l}106.47 \pm \\
34.26\end{array}$ & $\begin{array}{l}10.00- \\
210.57\end{array}$ & 0.28 & 0.18 \\
\hline & & SF & $61.71 \pm 5.50$ & $54.95 \pm 10.40 *$ & $\begin{array}{l}61.69 \pm \\
13.84\end{array}$ & $\begin{array}{l}11.32- \\
87.93\end{array}$ & -0.51 & 0.46 \\
\hline & $\begin{array}{l}\text { Artificial high } \\
\text { temperature }\end{array}$ & $\mathrm{SN}$ & $44.75 \pm 8.50$ & $\begin{array}{l}63.60 \pm \\
10.50 \star \star\end{array}$ & $\begin{array}{l}54.22 \pm \\
30.83\end{array}$ & $7.80-193.60$ & 1.45 & 3.59 \\
\hline & & SF & $28.87 \pm 5.50$ & $35.90 \pm 3.00 *$ & $\begin{array}{l}36.52 \pm \\
13.20\end{array}$ & $5.01-68.72$ & 0.09 & -0.37 \\
\hline & & HTN & $0.78 \pm 0.08$ & $0.80 \pm 0.05^{\star}$ & $0.84 \pm 0.18$ & $0.18-1.19$ & -0.41 & 0.53 \\
\hline & & HTA & $0.37 \pm 0.04$ & $0.51 \pm 0.06^{\star}$ & $0.50 \pm 0.18$ & $0.07-1.03$ & 0.13 & -0.23 \\
\hline
\end{tabular}

There were significantly positive correlations for all traits between two years, as shown by correlation coefficients range from $0.146-$ 0.417(Table 3). As expected, SF was significant positively correlated with SN, and negatively correlated with GN under different environments. There were significantly positive correlations between SF and HT under high temperature environments. In addition, strong and significant correlations were found in GN, SN, SF and HT under different temperature environments in two years. The correlation analysis demonstrated that these traits were stable and had high heritability from the control, natural and artificial high temperature environments.

Table 3. Correlation coefficients among SF in RILs populations under different environments 


\begin{tabular}{|c|c|c|c|c|c|c|c|c|c|c|c|}
\hline \multirow[t]{2}{*}{ Treatment } & \multirow[t]{2}{*}{ Traits } & \multicolumn{3}{|l|}{ Control } & \multicolumn{2}{|c|}{$\begin{array}{l}\text { Natural high } \\
\text { temperature }\end{array}$} & \multicolumn{2}{|c|}{$\begin{array}{l}\text { Artificial high } \\
\text { temperature }\end{array}$} & \multirow[t]{2}{*}{ HTN } & \multirow[t]{2}{*}{ HTA } & \multirow[b]{2}{*}{ HTN } \\
\hline & & $\mathrm{GN}$ & SN & SF & SN & SF & SN & SF & & & \\
\hline \multirow[t]{3}{*}{ Control } & $\mathrm{GN}$ & $0.310^{* *}$ & $0.715^{\star \star}$ & $-0.244^{\star \star}$ & $0.155^{\star}$ & $-0.172^{*}$ & $0.171^{\star}$ & -0.098 & - & - & \\
\hline & $\mathrm{SN}$ & $0.685^{* *}$ & $0.245^{\star \star}$ & $0.335^{\star *}$ & $0.208^{\star \star}$ & $0.251^{\star \star}$ & $0.215^{* *}$ & 0.001 & - & - & \\
\hline & SF & -0.085 & $0.307^{\star *}$ & $0.146^{\star}$ & 0.116 & $0.445^{* t}$ & 0.058 & $0.213^{* *}$ & $-0.310^{\star \star}$ & $-0.229^{\star *}$ & \\
\hline \multirow{2}{*}{$\begin{array}{l}\text { Natural } \\
\text { high } \\
\text { temperature }\end{array}$} & SN & 0.017 & $0.159^{\star}$ & $0.238^{\star \star}$ & $0.189 * *$ & $0.355^{\star \star}$ & $0.387^{\star \star}$ & 0.059 & - & - & \\
\hline & SF & -0.040 & $0.452^{* *}$ & $0.282^{* *}$ & $0.245^{\star \star}$ & $0.194^{* *}$ & $0.147^{\star}$ & $0.273^{* *}$ & $0.702^{\star \star}$ & $0.282^{\star \star}$ & \\
\hline \multirow{2}{*}{$\begin{array}{l}\text { Artificial } \\
\text { high } \\
\text { temperature }\end{array}$} & SN & 0.131 & $0.210^{\star *}$ & 0.132 & $0.169^{\star}$ & 0.138 & $0.173^{*}$ & $0.509^{\star \star}$ & - & - & \\
\hline & SF & $-0.195^{\star \star}$ & 0.141 & $0.270^{* *}$ & 0.027 & $0.280^{* *}=$ & $0.671^{\star \star}$ & $0.330 * *$ & $0.485^{\star \star}$ & $0.888^{\star *}$ & \\
\hline HTN & & - & - & $-0.426^{* *}$ & - & $0.730^{* *}$ & - & $\underline{0.061}$ & $0.417^{\star \star}$ & $0.268^{\star \star}$ & \\
\hline HTA & & - & - & $-0.149^{\star}$ & - & $\underline{0.132}$ & - & $\underline{0.874^{* *}}$ & $0.223^{\star \star}$ & $0.197^{* *}$ & \\
\hline
\end{tabular}

Lower and upper triangle data represent for 2019 and 2020; *and ** represent significant differences at the 5\% and 1\% level, respectively.

\section{QTL mapping within the RIL population}

A total of sixty-one QTLs were detected using the ICIM-ADD method, 25, 27 and 14 additive QTLs were identified under the control, natural and artificial high temperature conditions, respectively(Table 4, Fig. 2). These QTLs were located on chromosomes 1-8, 10 and 12, explained around 3.18-42.31\% of the phenotype variation. Twenty-five QTL were associated with the SF-related traits under control environments, 13 and 12 QTLs for 2019 and 2020, respectively. Among these QTLs, six QTLs were commonly detected in both years, the other QTLs only can be found in one environment. Ten QTLs associated with GN were identified on chromosomes 1, 4, 6, 8 and 10, these QTLs individually accounted for $4.82-15.84 \%$ of the phenotypic variance. Among these QTLs, only $q G N 1 a$, $q G N 4 b$ and $q G N 6$ were identified in different years, while the major QTL qGN1a has the highest phenotypic variation and additive effect. Nine putative QTLs associated with SN were detected on chromosomes 1, 4, 5, 6 and 8; among these, qSN1a, qSN1b and qSN4 were identified across two years. Six QTLs for SF were identified, and all of these QTLs only can be found in one environment; qSF2 and qSF4 have a higher phenotypic variation score, which contributed to $13.80 \%$ and $37.92 \%$ of phenotypic variation, respectively. 
Table 4

Putative QTLs for spikelet fertility related traits were detected in RILs population

\begin{tabular}{|c|c|c|c|c|c|c|c|c|c|}
\hline \multirow[t]{2}{*}{ Treatment } & \multirow[t]{2}{*}{ Trait } & \multirow[t]{2}{*}{ Locus } & \multirow[t]{2}{*}{ Marker } & \multicolumn{2}{|c|}{ LOD value } & \multicolumn{2}{|c|}{ PVE (\%) } & \multicolumn{2}{|c|}{ Additive effect } \\
\hline & & & & 2019 & 2020 & 2019 & 2020 & 2019 & 2020 \\
\hline \multirow[t]{19}{*}{ Control } & $\mathrm{GN}$ & qGN1a & RM428-RM323 & 6.13 & 5.80 & 11.48 & 15.84 & 20.07 & 18.13 \\
\hline & & $q G N 1 b$ & RM1198-RM1361.1 & & 2.85 & & 7.75 & & -16.91 \\
\hline & & qGN4a & RM471-RM1359 & & 5.86 & & 14.99 & & -19.47 \\
\hline & & $q G N 4 b$ & RM2441-R4M50 & 3.50 & 2.48 & 8.44 & 4.59 & -13.55 & -9.80 \\
\hline & & $q G N 6$ & RM111-STS6.2 & 2.49 & 4.12 & 7.97 & 13.26 & -16.61 & 18.08 \\
\hline & & qGN8 & RM3754-RM3496 & & 3.80 & & 10.83 & & -14.85 \\
\hline & & qGN10 & R10M40-STS10.3 & 3.03 & & 4.82 & & 13.19 & \\
\hline & SN & qSN1a & RM6902-RM428 & 6.89 & 2.91 & 9.41 & 6.88 & 18.39 & 9.13 \\
\hline & & $q S N 1 b$ & R1M37-RM3738 & 3.94 & 3.22 & 7.39 & 9.25 & 15.33 & -13.92 \\
\hline & & $q S N 4$ & RM1359-R4M43 & 2.82 & 5.82 & 3.18 & 18.84 & -10.35 & -16.90 \\
\hline & & $q S N 5$ & R5M13-RM3476 & 4.45 & & 10.86 & & 18.29 & \\
\hline & & $q S N 6$ & RM217-RM111 & & 2.66 & & 5.85 & & 9.39 \\
\hline & & qSN8 & RM3754-RM3496 & & 2.70 & & 7.79 & & -9.70 \\
\hline & SF & $q S F 1$ & RM8097-STS1.4 & 3.14 & & 7.19 & & -5.05 & \\
\hline & & $q S F 2$ & STS2.4-RM13603 & 6.58 & & 13.80 & & -9.00 & \\
\hline & & qSF3 & МM3720-ММ3778 & & 3.07 & & 9.52 & & 4.67 \\
\hline & & $q S F 4$ & RM5688-RM471 & & 2.59 & & 37.92 & & -9.97 \\
\hline & & qSF10 & RM3451-RM590 & 3.05 & & 4.37 & & 5.00 & \\
\hline & & qSF12 & RM247-RM7003 & 4.18 & & 5.78 & & 5.66 & \\
\hline \multirow[t]{12}{*}{ Nature high temperature } & SN & $q S N 1$ & RM7180-RM6703 & 2.68 & 3.45 & 4.27 & 9.89 & -9.82 & -14.08 \\
\hline & & $q S N 2 a$ & RM3732-RM1361.2 & & 3.06 & & 6.88 & & 12.07 \\
\hline & & $q S N 2 b$ & STS2.3-STS2.4 & & 2.60 & & 6.04 & & 8.55 \\
\hline & & $q S N 3$ & STS3.6-STS3.7 & & 4.20 & & 11.42 & & 13.41 \\
\hline & & $q S N 6$ & RM111-STS6.2 & 2.51 & & 4.28 & & 9.47 & \\
\hline & & qSN12 & RM101-STS12.1 & 2.59 & & 8.42 & & -12.03 & \\
\hline & SF & $q S F 2$ & STS2.4-RM13603 & 2.74 & & 5.98 & & 7.55 & \\
\hline & & qSF3 & RM1350-RM3199 & 3.26 & & 9.39 & & 4.98 & \\
\hline & & $q S F 7$ & R7M37-RM1132 & 2.90 & & 7.43 & & -4.16 & \\
\hline & & qSF12 & RM7003-RM101 & 2.89 & 2.50 & 6.40 & 11.20 & -7.57 & -9.32 \\
\hline & HTN & qHTN2 & RM13603-ID2 & 2.66 & & 7.06 & & 0.11 & \\
\hline & & qHTN12 & RM247-RM7003 & 3.34 & 2.60 & 7.13 & 11.45 & -0.10 & -0.15 \\
\hline \multirow[t]{4}{*}{ Artificial high temperature } & SN & $q S N 4$ & R4M43-RM3288 & 2.90 & 3.73 & 10.54 & 9.88 & -9.50 & -8.83 \\
\hline & & qSN7 & RM5055-RM5711 & & 2.67 & & 8.20 & & 9.57 \\
\hline & & qSN10 & RM3451-RM590 & 2.74 & & 6.68 & & 4.72 & \\
\hline & SF & $q S F 2$ & STS2.4-RM13603 & & 2.92 & & 42.31 & & -10.04 \\
\hline
\end{tabular}




\begin{tabular}{|c|c|c|c|c|c|c|c|c|c|}
\hline \multirow[t]{2}{*}{ Treatment } & \multirow[t]{2}{*}{ Trait } & \multirow[t]{2}{*}{ Locus } & \multirow[t]{2}{*}{ Marker } & \multicolumn{2}{|c|}{ LOD value } & \multicolumn{2}{|c|}{ PVE (\%) } & \multicolumn{2}{|c|}{ Additive effect } \\
\hline & & & & 2019 & 2020 & 2019 & 2020 & 2019 & 2020 \\
\hline & & qSF3 & & & 2.53 & & 6.61 & & 3.95 \\
\hline & & & RM3199-RM1352 & & & & & & \\
\hline & & qSF6 & RM1340-R6M44 & 2.79 & & 6.55 & & 3.80 & \\
\hline & & $q S F 7$ & RM8261-RM1209 & & 2.53 & & 6.17 & & -3.84 \\
\hline & & qSF8 & RM3754-RM3496 & & 2.88 & & 10.11 & & -4.87 \\
\hline & & qSF12 & RM7003-RM1337 & 3.01 & 2.64 & 9.50 & 10.23 & 4.75 & 4.91 \\
\hline & HTA & qHTA1 & R1M30-RM3240 & 2.70 & 2.65 & 7.54 & 5.07 & 0.10 & 0.07 \\
\hline & & qHTA3 & ММ3720-ММ3778 & & 2.81 & & 6.73 & & -0.08 \\
\hline & & qHTA6 & RM111-STS6.2 & 2.63 & & 5.31 & & -0.09 & \\
\hline & & qHTA12 & RM7003-RM1337 & & 2.59 & & 12.64 & & -0.20 \\
\hline
\end{tabular}

Twenty-seven QTLs were associated with heat tolerance-related traits under natural high temperature environments. Seven additive QTLs identified for SN were detected on chromosomes 1, 2, 3, 6 and 12, except for qSN1 which was found in both years and explaining - 9.82 and - 14.08 of the phenotypic variation, all other QTLs were only detected in one environment. Four QTLs associated with SF, namely $q S F 2$, qSF3, qSF7 and qSF12, were detected on chromosomes 2, 3, 7, and 12 respectively. Among these QTLs, the stable expressed major QTL qSF12 has a higher LOD value and phenotypic variation, the other QTLs can be detected only in one environment. Two QTLs associated with HTN were detected, among which qHTN12 with the greatest effect on phenotypic variation was collocated with the QTL qSF12.

Sixteen QTLs associated with the heat tolerance-related traits were identified under artificial high temperature environments, 6 and 10 QTL in 2019 and 2020, respectively. Three QTLs associated with SN were detected on chromosomes 4, 7 and 10, and these QTLs can be identified in one environment, which explained $6.68-9.88 \%$ of phenotypic variance. Seven putative QTLs associated with SF were detected on chromosomes $2,3,6,7,8$, and 12. Among these QTLs, only $q S F 12$ was located in two years. Four QTLs associated with HTA were detected, that is qHTA1, qHTA3, qHTA6 and qHTA12 located on chromosomes 1, 3, 6 and 12, respectively. Among these QTLs, only $q H T A 1$ can be found in two years.

Our results reveal that pleiotropic effects and QTL hotspots are the key factors affecting GN and SF in rice, and then these traits may have a similar genetic regulation. We could assign the 64 QTLs to 15 chromosome regions, each corresponding region contains about 4 QTLs. Seven major QTL clusters were assembled on the chromosomes 1, 2, 3, 4, 6 and 12, which contain 38 QTLs, accounting for $59.38 \%$ of the whole locus. These related QTLs were identified in previous studies. Among these QTLs, clusters $q H T S F 1 a, q H T S F 1 b$, qHTSF4 and $q H T S F 12$ were stably detected (Table 5, Fig. 2).

Table 5

Heat tolerance-related traits of QTL hotspot and pleiotropic region

\begin{tabular}{|lllll|}
\hline Major QTL cluster & Chr. & Interval & Pleiotropic QTL & Related reports \\
\hline qHTSF1a & 1S & RM3740-RM323 & qGNC1a,qSNC1a,qGNN1,qGNA1 & Gn1a (Ashikari et al.,2005) \\
\hline qHTSF1b & 1L & RM3240-RM1198 & qGNC1b,qSNC1b,qSFC1,qSNN1,qHTA1 & qHBT1-1 (Cao et al., 2020) \\
\hline qHTSF2 & 2 & STS2.4-RM13603 & qSNC2,qSFC2,qSNN2,qSFN2,qHTN2,qSFA2 & - \\
\hline qHTSF3 & 3 & R3M30-RM1350 & qSFC3,qSFN3,qSFA3,qHTA3 & qSF3.2 (Nubankoh et al., 2020) \\
\hline qHTSF4 & 4 & RM471-RM3288 & qGNC4,qSNC4,qSFC4,qGNN4,qGNA4,qSNA4 & qHTS4.1 (Ye et al., 2015b) \\
\hline qHTSF6 & 6 & RM111-STS6.2 & qGNC6,qSNC6,qGNN6,qSNN6,qHTA6 & qHTSF6.1 (Raza et al., 2020) \\
\hline qHTSF12 & 12 & RM247-RM101 & qSFC12,qSNN12,qSFN12,qHTN12,qSFA12 & - \\
\hline The bold represent the stable QTL under different environments, respectively. & \\
\hline
\end{tabular}


In this study, 17 pairs of epistatic interaction QTLs for heat tolerance-related traits were detected (Table 6). All these QTLs are located on chromosomes 1, 2, 3, 4, 5, 6, 7, 8, 9 and 12, and LOD value of these QTLs range from 6.7 to 12.9, accounting for a wide phenotypic variation ranging from 8.32-28.09\%. 13 out of 17 epistatic QTL pairs were nearby the additive QTL. For example, the genomic region RM5688-RM471 on the chromosome 4 is interacted with the chromosomes 2, 3, 5,7, 8,11 and 12; the genomic region RM1361-RM6321 on chromosome 1 epistatic effection on the chromosomes 2,4,8 and 12. There were 8 pairs of epistatic interaction QTL for HT (HTN and HTA), no epistatic QTL of epistatic interaction for SF under natural and artificial high temperature stress. Therefore, epistatic QTLs played an essential role in controlling the genetic expression of the heat tolerance gene.

Table 6

Identification and analysis of the epistatic interaction QTL under different temperature environments

\begin{tabular}{|c|c|c|c|c|c|c|c|c|}
\hline Environments & Trait & Chr.i & Marker1 & Chr.j & Marker2 & LOD & PVE(\%) & AA \\
\hline \multirow[t]{2}{*}{ Control } & $\mathrm{GN}$ & 1 & STS1.4-RM7180 & 9 & RM7048-STS9.1 & 5.91 & 12.39 & 17.90 \\
\hline & SF & 1 & RM1361-RM6321\# & 4 & R4M43-RM3288 & 7.29 & 23.35 & -9.70 \\
\hline \multirow[t]{5}{*}{ Nature high temperature } & SN & 12 & RM247-RM7003"\# & 6 & RM587-RM217 & 5.95 & 16.62 & -30.98 \\
\hline & HTN & 1 & RM1198-RM1361\# & 2 & STS2.4-RM13603 & 9.64 & 15.09 & -0.43 \\
\hline & & 1 & RM1198-RM1361\# & 12 & STS12.2-RM1226 & 12.19 & 13.69 & 0.43 \\
\hline & & $4^{\#}$ & RM5688-RM471 & 2 & RM5699-RM1358 & 11.15 & 8.32 & -0.43 \\
\hline & & $4^{\#}$ & RM5688-RM471 & 11 & RM21-STS11.4 & 10.21 & 18.23 & 0.39 \\
\hline \multirow[t]{10}{*}{ Artificial high temperature } & SN & 1 & STS1.3-RM306 & 2 & RM7451-STS2.1 & 6.33 & 13.36 & -19.89 \\
\hline & & 1 & R1M30-RM3240 & 3 & RM3199-RM1352 & 6.38 & 15.69 & -23.34 \\
\hline & & $4^{\#}$ & RM5688-RM471 & 5 & R5M13-RM3476 & 7.09 & 19.92 & 26.81 \\
\hline & & $4^{\#}$ & RM5688-RM471 & 7 & RM1132-RM8261 & 6.85 & 23.04 & -31.10 \\
\hline & & $4^{\#}$ & RM5688-RM471 & $12^{\#}$ & RM19-RM247 & 7.34 & 25.68 & -31.36 \\
\hline & & 7 & RM5711-STS7.1 & 8 & RM5556-RM6208 & 6.45 & 21.45 & -24.61 \\
\hline & HTA & 1 & RM1361-RM6321\# & 8 & RM1376-RM4085 & 20.71 & 26.72 & -0.72 \\
\hline & & $4^{\#}$ & RM5688-RM471 & 7 & RM3826-R7M37 & 22.56 & 25.12 & -0.70 \\
\hline & & $4^{\#}$ & RM5688-RM471 & 8 & RM6208-RM3395 & 21.26 & 22.85 & -0.69 \\
\hline & & 8 & RM1376-RM4085 & $12^{\#}$ & RM19-RM247 & 18.55 & 28.09 & -0.71 \\
\hline
\end{tabular}

\section{Identify the major QTLs through BSA}

BSA method was proved to be a convenient method to the detection of major QTLs, in particular to identification of QTLs for adversity stresses such as drought, salinity, heat and cold (Zhang et al., 2009; Sandhu et al.,2014; Sun et al. 2018; Wu et al., 2019). In this study, SF and HT were used to evaluate the heat tolerance, two extreme bulks, including the heat-tolerant bulk with higher SF and HTA, and the heatsensitive bulk with lower SF and HT under artificial high temperature conditions. 10 lines with heat tolerance and sensitivity were selected in the $\mathrm{F}_{5: 6}$ populations (510 lines), respectively. The SF and HTA were significantly lower in the S-bulk than in the T-bulk, indicating that the overall phenotypic of the S-bulk was greatly affected by high temperature (Fig. 3). 24 markers have polymorphism from two bulks and the parents, which have clear correspondence with phenotype. Out of these markers, 11 markers were together located on the chromosomes 1 , 2 and 12, namely three putative QTLs, qSF1, qSF2 and qSF12, these QTLs exhibited the contrasting genotype between the T-bulk and S-bulk, respectively (Fig. 4A). Through BSA, it was found that these QTLs revealed the highly significant correlation among these addictive QTLs through ICMI mapping methods, which further confirmed the reliability of the detected QTLs (Fig. 4B).

\section{Discussion}




\section{Identification method of heat tolerance in rice}

Rice is one of the most important food crops in the world. Therefore, maintaining high yield of rice plays an important role in food security (Khush, 2005). However, global warming threatens many aspects of human life. It also becomes a big concern in sustaining and improving rice yields. Breeding heat-tolerant rice is a fundamental way to help address this challenge (Yan et al. 2020; Zhao et al., 2016). High temperature was already a major environmental limiting factor affecting yield and rice is highly susceptible to heat stress at the reproductive stage (Tian et al. 2009; Prasad et al. 2017; Fang et al., 2020). High temperature causes irreversible damage by retarding anther dehiscence, pollen fertility, pollen tube elongation in pollinated pistils, spikelet fertility and grain filling (Jagadish et al. 2007; Zhang et al. 2018), and different cultivars respond differently to high temperature stress, while these differences are largely controlled by genetic factors (Prasad et al. 2006; Yan et al., 2020; Ye et al., 2015). One of the best strategies for maintaining rice productivity under increasing temperature is to develop heat-tolerant varieties (Kilasi et al. 2018). In this study, ZYZ8 was a heat-tolerant and high-yielding cultivar, and LD5 was a heatsensitive cultivar under both natural and artificial high temperature. High temperature has different degrees of effection SF and HT, the latter has strong heat stress, and then heat tolerance of mechanism from different treatments methods maybe different. In the RIL population, the $\mathrm{SN}, \mathrm{SF}$ and HT values have a normal frequency distribution, have a large variation and transgressive segregations in response to high temperature. There were significant positive correlations between SF and HT under the natural and artificial high temperature environments. Heat-tolerant lines contain some major QTL with higher SF and HTA, while the heat-sensitive lines have a few or no related QTLs with lower $\mathrm{SF}$ and HT under high temperature conditions. Therefore, the main step of breeding heat tolerant cultivars is selecting and identifying extremely heat resistant germplasm resources or genes.

To clone and apply the major QTL of heat tolerance, the most critical step is quickly and accurately identifying heat resistance phenotype. A standardized temperature treatment for phenotyping is very useful for accurately evaluating the heat tolerance of promising populations and breeding lines, and making the results more comparable. In the past twenty years, the natural, greenhouse and chamber high temperature conditions have been used to screening penotype and identify QTL for heat tolerance (Chen et al. 2008, Zhang et al. 2009, Jagadish et al. 2010a, Xiao et al. 2011). The high temperature in the growth chamber is more accurate and stable, the results from different research groups become more comparable when different mapping populations. However, more plants could be treated with limited space (Ye et al. 2010). Compared with the natural and greenhouse high temperature methods, the chamber method used to evaluate heat tolerance for phenotyping the genetic and nature populations is very efficient. However, this method cannot be used for evaluating the heat tolerance of big germplasm resources populations and advanced breeding lines of rice (Li et al., 2018). In most of the earlier studies, SF under the high temperature environments was taken as the main criterion for selecting heat-tolerant genotypes, but in our study, the GN, SN, SF and HT under the natural and greenhouse high temperature were used to evaluate heat resistance of each line. The GN, SF and TGW were correlated with yield under both normal and heat stress conditions. Overall results showed positive correlation between SF and yield per plant only in heat stress conditions but not in normal conditions. HT have been regard as the heat tolerance evaluation index under the natural and greenhouse high temperature, which can eliminate the effects of the SF under the normal environment, so that the HT can be used to truly and accurately reflect the heat resistance. Hence, the major QTL cluster control with these traits can be used for the key chromosome regions of yield under heat stress.

\section{Heat tolerance QTLs at the reproductive stage}

High temperature stress, as an increasingly important problem in crop production, can significantly reduce crop yield (Xu et al. 2017; Aleem et al., 2020; Karwa et al. 2020). Rice is known to be sensitive to heat stress particularly at the heading and flowering stage, SF and thousandgrain weight have a significant decreased under high temperature Rice heat tolerance during different development stages is a quantitative trait controlled by multiple micro-QTL (Jagadish et al., 2010; Li et al. 2018; Ravikiran et al., 2020). QTLs for rice heat tolerance at the flowering stage have been mapped on all chromosomes by using various rice populations and high temperature treatment methods (Cheng et al. 2012; Ye et al., 2015a; Li et al. 2018). 11 QTLs were identified in three populations, and then the distribution of these QTLs in chromosomes 1, 2, 3, 4, 6 and 11, qHTSF4.1 was consistently detected across different genetic backgrounds and could be an important source for enhancing heat tolerance in rice at flowering stage (Ye et al., 2015b). According to Cheng et al(2012) introgression lines derived from a cross between Xiushui 09 and IR2061 were put into greenhouse and subjected to heat treatment, four QTLs for SF were identified on chromosomes 4, 5, 6 and 11. Among these QTLs, qSF4 and qSF6 reduced SF under heat stress and normal conditions. Li et al (2018) used the RIL population exposed to high temperature at the heating and flowering stage. QTL analysis revealed 11 QTLs associated with heat tolerance, which located on chromosomes 1, 3, 4, 5 and 6, and found 13 QTLs with epistatic interactions and nine QTLs with environmental interactions. In our study, 61 QTLs were detected on chromosomes 1-8, 10 and 12 under three different temperature treatment environments; among these QTLs, 12 QTLs were stably expressed in different years, the other QTLs only can be found in one year. These major QTL clusters distributed on chromosomes 1, 2, 3, 4, 6 and 12, namely qHTSF1a qHTSF1b qHTSF2 qHTSF3 qHTSF4 qHTSF6 and qHTSF12. In addition, 17 QTLs with epistatic interactions were detected, and the major QTLs were all involved in epistatic interactions, which showed that the epistatic interactions have important effects on regulation of rice SF and HT. Recently, more than 200 heat tolerance-

Page $10 / 16$ 
related QTLs have already identified from the previous published papers and http://www.gramene.org/, compared these QTL identified with our research, we found that chromosomal distributions and locations of the QTL clusters qHTSF1a, qHTSF1b, qHTSF3, HTSF4 and qHTSF6 are similar to that of Gn1a, qHBT1-1, qSF3.2, qHTSF4.1 and qHTSF6.1 (Ashikari et al., 2005; Cao et al., 2020; Nubankoh et al., 2020; Ye et al., 2015b; Raza et al., 2020). The major QTL qHTSF2 and qHTSF12 are two novelly identified major QTLs, and $q H T S F 12$ can be found in different environments.

BSA method was proved to be a convenient technology in detecting major QTLs, in particular for identify resistance QTLs (IIla-Berenguer et al., 2015; Yao et al., 2016; Nubankoh et al.,2020). Recently, an effective approach QTL-seq has been developed to rapidly identify QTLs in plants. It combines the potential of BSA method and the power of high-throughput whole-genome resequencing to locate genomic regions in the two bulk populations that contain 10-20 individual plants with extreme phenotypes in each bulk (Takagi et al. 2013; Illa-Berenguer et al., 2015). Nubankoh et al.(2020) applied the QTL-seq method to rapidly identify QTLs for SF under high-temperature stress based on an $F_{2}$ population, three QTLs were fine mapped on chromosomes 1, 2 and 3, and then candidate genes for each QTL were proposed and were supported. In our study, the BSA method was used to check the heat tolerance QTL for its authenticity and correctness. First, a total of 750 markers from the rice molecular map were subjected to polymorphism surveys involving, of which 24 pairs exhibited polymorphism from the parents and two bulks, and then these markers were together located on chromosomes 1, 2 and 12. Through BSA, three QTLs qSF1, qSF2 and $q S F 12$ revealed the highly significant correlation among these addictive QTL clusters $q H T S F 1, q H T S F 2$ and $q H T S F 12$, which further confirmed the reliability of the detected QTL. Hence, the BSA method without the laborious and time-consuming step of genotyping of a whole population to construct a genetic linkage map and with the feasibility to be applied to any segregating population, has been successfully used to rapidly identify the major QTL in rice. qHTSF1, qHTSF2 and qHTSF12 was three important QTLs for control the heat tolerance, so that we will developbackcross populations to introduce the QTLs into LD5 background for further validation and fine mapping these QTLs.

\section{Declarations}

\section{Acknowledgements}

This work was supported by the National Key Research and Development Program of China (2016YFD0100101, 2016YFD0100301, 2016YFD0100101-11), Collaborative Innovation Special Project of Jiangxi Modern Agricultural Research (JXXTCX202101), National Crop Germplasm Resources Center (NCGRC-2020-02, NICGR2021-077) Protective Program of Crop Germplasm of China (2019NWB036-01, 2019NWB036-12-2).

Data Availability All data included in this study are available upon request by contact with the corresponding author.

Animal Research (Ethics) Not applicable

Consent to Participate (Ethics) Not applicable

Consent to Publish (Ethics) Not applicable

Plant Reproducibility Not applicable

Clinical Trials Registration Not applicable

Author Contribution Jin Liu conducted the field work, generated phenotypic data, preformed data analysis and wrote the manuscript; Huiying Zhou, JiaxiaoHu and Shuhui Li helped for field work and generated phenotypic data; Xiaoding Ma, Di Cui and Bing Han helped for field work and preformed data analysis; Maomao Li and Longzhi Han designed the research, guided the experiments and manuscript revision. All authors read and approved the final version.

Conflict of Interest The authors declare that they have no competing interests.

\section{References}

1. Aleem S, Sharif I, Amin E, Tahir M, Parveen N, Aslam R, Najeebullah M, Shahid MTH. Heat tolerance in vegetables in the current genomic era: an overview. Plant Growth Regulation, 2020, 92:497-516.doi:10.1007/s10725-020-00658-5

2. Kobayashi A, Sonoda J, Sugimoto K, Kondo M, Iwasawa N, Hayashi T, Tomita K, Yano M, Shimizu T. Detection and verification of QTLs associated with heat-induced quality decline of rice (Oryza sativa L.) using recombinant inbred lines and near-isogenic lines. Breed Sci, 2013, 63:339-346. doi:10.1270/jsbbs.63.339

Page $11 / 16$ 
3. Ashikari M, Sakakibara H, Lin SY, YamamotoT, Takashi T, Nishimura A, Angeles ER, Qian Q, Kitano H, Matsuoka M. Cytokinin oxidase regulates rice grain production. Science, 2005, 309(741): 741-745. doi:10.1126/science.1113373

4. Cao ZB, Li Y, Tang HW, Zeng BH, Tang XY, Long QZ, WuXF, Cai YH, Yuan LF, Wan JL. Fine mapping of the QTL qHTB1-1, which confers heat tolerance at the booting stage, using an Oryza rufipogon Griff. introgression line. Theoretical and Applied Genetics, 2020, 133:1161-1175. doi: 10.1007/s00122-020-03539-7

5. Cheabu S, Panichawong N, Rattanametta P, Wasuri B, Kasemsap P, Arikit S, Vanavichit A, Malumpong C. Screening for spikelet fertility and validation of heat tolerance in a large rice mutant population. Rice Science, 2019, 26(4): 229-238. doi:10.1016/j.rsci.2018.08.008

6. Cheng LR, Wang JM, Uzokwe V, Meng LJ, Wang Y, Sun Y, Zhu LH, Xu JL, Li ZK. Genetic analysis of cold tolerance at seedling stage and heat tolerance at anthesis in rice (Oryza sativa L.). Journal of Integrative Agriculture, 2012, 11(3): 359-367.doi:10.1016/S20953119(12)60020-3

7. Das S, Krishnan P, Nayak M, Ramakrishnan B. High temperature stress effects on pollens of rice (Oryza sativa L.) genotypes. Environ Exp Bot, 2014, 101:36-46.doi:10.1016/j.envexpbot.2014.01.004

8. Fang GN, Yang SL, Ruan BP, Liu CL, Zhang AP, Jiang HZ, Ding SL, TianB, Zhang Y, Jahan N, Zhu L, Zhang GH, Dong GJ, Zhang Q, Zeng DL, Guo LB, Gao ZY, Qian Q. Isolation of TSCD11 gene for early chloroplast development under high temperature in rice. Rice, 2020, 13:49. doi:10.1186/s12284-020-00411-6

9. Fu GF, Feng BH, Zhang CX,Yang YJ, Yang XQ, Chen TT, Zhao X, Zhang XF, Jin QY, Tao LX. Heat stress is more damaging to superior spikelets than inferiors of rice (Oryza sativa L.) due to their different organ temperatures. Front. Plant Sci.

7:1637.doi:10.3389/fpls.2016.01637

10. Ye CR, Argayoso MA, Redoña ED, Sierra SN, LazaMA, Dilla CJ, Mo Y, Thomson MJ, Chin J, Delaviña CB, Diaz GQ, Hernandez JE. Mapping QTL for heat tolerance at flowering stage in rice using SNP marker. Plant Breeding, 2012, 131:33-41.doi:10.1111/j.14390523.2011.01924.x

11. Huang J, Zhang FM, Xue Y. Recent changes of rice heat stress in Jiangxi province, southeast China. Int J Biometeorol, 2017, 61:623-633 .doi:10.1007/s00484-016-1239-3

12. Illa-Berenguer E, Houten JV, Huang ZJ, Knaap EVD. Rapid and reliable identification of tomato fruit weight and locule number loci by QTL-seq. Theor Appl Genet, 2015,128:1329-1342. doi:10.1007/s00122-015-2509-x

13. Jagadish SVK, Cairns J, Lafitte R, Wheeler TR, Price AH,Craufurd PQ. Genetic analysis of heat tolerance at anthesis in rice. Crop Sci, 2010, 50(5):1633-1641.

14. Jagadish SVK, Craufurd PQ, Wheeler TR. High temperature stress and spikelet fertility in rice (Oryza sativa L.). J Exp Bot, 2007, 58(7):1627-1635. doi:10.1093/jxb/erm003

15. Karwa S, Bahuguna RN, Chaturvedi AK, Maurya S, Arya SS, Chinnusamy V, Pal M. Phenotyping and characterization of heat stress tolerance at reproductive stage in rice (Oryza sativa L.). Acta Physiologiae Plantarum, 2020, 42:29. doi:10.1007/s11738-020-3016-5

16. Li GY, Zhang CX, Zhang GH, Fu WM, Feng BH, Chen TT, Peng SB, Tao LX, Fu GF. Abscisic acid negatively modulates heat tolerance in rolled leaf rice by increasing leaf temperature and regulating energy homeostasis. Rice, 2020,13:18.

17. Li MM, Li X, Yu LQ, Wu JW, Li H, Liu J, Ma XD, Jo SM, Park DS, Song Y, Han LZ. Identification of QTLs associated with heat tolerance at the heading and flowering stage in rice (Oryza sativa L.). Euphytica, 2018, 214:70. doi:10.1007/s10681-018-2136-0

18. Mba C, Guimaraes EP, Ghosh K. Re-orienting crop improvement for the changing climatic conditions of the 21st century. Agric Food Secur, 2012, 1:7. doi:10.1186/2048-7010-1-7

19. McCouch SR. Gene nomenclature system for rice. Rice, 2008, 1: 72-84. doi:10.1007/s12284-008-9004-9

20. Nubankoh P, Wanchana S, Saensuk C, Ruanjaichon V, Cheabu S, Vanavichit A, Toojinda T, Malumpong C, Arikit S. QTL-seq reveals genomic regions associated with spikelet fertility in response to a high temperature in rice (Oryza sativa L.). Plant Cell Reports, 2020, 39:149-162. doi:10.1007/s00299-019-02477-z

21. Peng SB, Huang JL, Sheehy JE, Laza RC, Visperas RM, Zhong XH, Centeno GS, Khush GS, CassmanKG. Rice yields decline with higher night temperature from global warming. PNAS, 2004, 101(27):9971-9975.

doi:10.1073/pnas.0403720101

22. Rang ZW, Jagadish SVK, Zhou QM, Craufurd PQ, Heuer S. Effect of high temperature and water stress on pollen germination and spikelet fertility in rice. Environ Exp Bot, 2011,70:058-65. doi:10.1016/j.envexpbot.2010.08.009

23. Ravikiran KT, Krishnan SG, Vinod KK, Dhawan G, Dwivedi P, Kumar P, Bansal VP, Nagarajan M, Bhowmick PK, Ellur RK, Bollinedi H, Pal M, Mithra ACR, Singh AK. A trait specific QTL survey identifies NL44, a NERICA cultivar as a novel source for reproductive stage heat stress tolerance in rice. Plant Physiol. Rep. 2020, 25(4):1-13.doi:10.1007/s40502-020-00547-z

Page 12/16 
24. Raza Q, Riaz A, Bashir K, Sabar M. Reproductive tissues-specific meta-QTLs and candidate genes for development of heat-tolerant rice cultivars. Plant Molecular Biology, 2020, 104:97-112. doi:10.1007/s11103-020-01027-6

25. Sandhu N, Singh A, Dixit S, Cruz MTS, Maturan PC, Jain RK, Kumar A. Identification and mapping of stable QTL with main and epistasis effect on rice grain yield under upland drought stress. BMC Genetics, 2014, 15:63.doi:10.1186/1471-2156-15-63

26. Sun J, Yang LM, Wang JG, Liu HL, Zheng HL, Xie DW, Zhang MH, Feng MF, Jia Y, Zhao HW, Zou DT. Identification of a cold-tolerant locus in rice (Oryza sativa L.) using bulked segregant analysis with a next-generation sequencing strategy. Rice, 2018, 11:24.doi:10.1186/s12284-018-0218-1

27. Takagi H, Abe A, Yoshida K, ShunichiK, Satoshi N, Chikako M, Aiko U, Hiroe U, Muluneh T, Shohei T , Hideki I, Liliana C, Sophien K, Ryohei T. QTL-seq: rapid mapping of quantitative trait loci in rice by whole genome resequencing of DNA from two bulked populations. Plant J, 2013, 74:174-183. doi:10.1111/tpj.12105

28. Talukder SK, Babar MA, Vijayalakshmi K, Poland J, Prasad PVV, Bowden R, Fritz A. Mapping QTL for the traits associated with heat tolerance in wheat (Triticum aestivum L.). BMC Genetics 2014, 15:97. doi:10.1186/s12863-014-0097-4

29. Tazib T, Kobayashi Y, Koyama H, Matsui T. QTL analyses for anther length and dehiscence at flowering as traits for the tolerance of extreme temperatures in rice (Oryza sativa L.). Euphytica, 2015, 203:629-642. doi:10.1007/s10681-014-1291-1

30. Teixeira El, Fischer G, Velthuizen HV, Walter C, Ewert F. Global hot-spots of heat stress on agricultural crops due to climate change. Agrl Meteorol, 2013, 170: 206-215. doi:10.1016/j.agrformet.2011.09.002

31. Terao T, Hirose T. Temperature-dependent QTLs in indica alleles for improving grain quality in rice: increased prominence of QTLs responsible for reduced chalkiness under high-temperature conditions. Mol Breeding, 2018, 38: 52. doi:10.1007/s11032-018-0807-0

32. Trnka M, Rötter RP, Ruiz-Ramos M. Adverse weather conditions for European wheat production will become more frequent with climate change. Nat Clim Chang, 2014, 4: 637-643. doi:10.1038/nclimate2242

33. Vikram P, Swamy BPM, Dixit S, Ahmed H, Cruz MTS, Singh AK, Ye GY, Kumar Al. Bulk segregant analysis: an effective approach for mapping consistent-effect drought grain yield QTLs in rice. Field Crops Res. 2012;134:185-192. doi:10.1016/j.fcr.2012.05.012

34. Wahid A, Gelani S, Ashraf M, Foolad MR. Heat tolerance inplants:anoverview. Environ.Exp.Bot., 2007, 61, $199-223$. doi:10.1016/j.envexpbot.2007.05.011

35. Wang JK, Li HH, Zhang LY, Meng L. QTL ICI Mapping V4.2. http://www.isbreeding.net, 2019.

36. Wang P, Zhang Z, Song X,Hu SB, Chen HZ, Xiang J, Zhang YK, Zeng YJ, Shi QH, Zhu DF, Zhang YP. Temperature variations and rice yields in China: historical contributions and future trends. Clim Chang, 2014, 124(4):777-789. doi:10.1007/s10584-014-1136-X

37. Wang YL, Wang L, Zhou JX, Hu SB, Chen HZ, Xiang J, Zhang YK, Zeng YJ, Shi QH, Zhu DF, Zhang YP. Research progress on heat stress of rice at flowering stage. Rice Science, 2019, 26(1):1-10.

38. Wu SL, Qiu J, Gao QK. QTL-BSA: A bulked segregant analysis and visualization pipeline for QTL-seq. Interdisciplinary Sciences: Computational Life Sciences, 2019, 11:730-737. doi:10.1007/s12539-019-0 0344-9

39. Xiao YH, Pan Y, Luo LH, Zhang GL, Deng HB, Dai LY, Liu XL, Tang WB, Chen LY, Wang GL. Quantitative trait loci associated with seed set under high temperature stress at the flowering stage in rice (Oryza sativa L.). Euphytica, 2011, 178:331-338.doi:10.1007/s10681-0100300-2

40. Xu JM, Driedonks N, Rutten MJM, Vriezen WH, Boer GJD, Rieu I. Mapping quantitative trait loci for heat tolerance of reproductive traits in tomato (Solanum lycopersicum). Mol Breeding, 2017, 37: 58. doi:10.1007/s11032-017-0664-2

41. Yan C, Zhan GP, Hong XF, Yang DW. Identification and fine mapping of a major QTL, TT1-2, that plays significant roles in regulating heat tolerance in rice. Plant Molecular Biology Reporter, 2020, (1):1-10. doi: 10.1007/s11105-020-01256-5

42. Yao XY, Li Q, Liu J, Jiang SK, Yang SL, Wang JY, Xu ZJ. Dissection of QTLs for plant height and panicle length traits in rice under different environment. Sci Agric Sin, 2015,48(3): 407-414.(in Chinese with English abstract)

43. Ye CR, Tenorio FA, Argayoso MA, Laza MA, Koh HJ, Redoña ED, Jagadish KSV,Gregorio GB. Identifying and confirming quantitative trait loci associated with heat tolerance at flowering stage in different rice populations. BMC Genetics, 2015,16:41.doi: 10.1186/s12863-0150199-7

44. Ye CR, Tenorio FA, Redo ED, Morales-Cortezano PS, Cabrega GA, Jagadish KSV, Gregorio GB. Fine mapping and validating qHTSF4. 1 to increase spikelet fertility under heat stress at flowering in rice. Theor Appl Genet, 2015, 128:1507-1517. doi: 10.1007/s00122-015-25269

45. Zhang GL, Chen LY, Xiao GY, Xiao YH, Chen XB, Zhang ST. Bulked segregant analysis to detect QTL related to heat tolerance in rice (Oryza sativa L.) using SSR markers. Agric. Sci. China, 2009, 8:482-487. doi: 10.1016/S1671-2927(08)60235-7

46. Zhang H, Duan L, Dai JS, Zhang CQ, Li J, Gu MH, Liu QQ, Zhu Y. Major QTLs reduce the deleterious effects of high temperature on rice amylose content by increasing splicing efficiency of Wx pre-mRNA. Theor Appl Genet, 2014, 127:273-282. doi: 10.1007/s00122-013-

Page 13/16 
47. Zhao L, Lei JG, Huang YJ, Zhu S, Chen HP, Huang RL, Peng ZQ, Tu QH, Shen XH, Yan S. Mapping quantitative trait loci for heat tolerance at anthesis in rice using chromosomal segment substitution lines. Breeding Science, 2016, 66: 358-366.doi: 10.1270/jsbbs.15084

48. Zhao L, Zhao CF, Zhou LH, Lin J, Zhao QY, Zhu Z, Chen T, Yao S, Hasegawa T, Matsui T, Wang CL. QTL mapping of dehiscence length at the basal part of thecae related to heat tolerance of rice (Oryza sativa L.). Euphytica, 2016, 209:715-723.doi: 10.1007/s10681-016-16648

49. Zhu S, Huang RL, Wai HP, Xiong HL, Shen XH,He HH, Yan S. Mapping quantitative trait loci for heat tolerance at the booting stage using chromosomal segment substitution lines in rice. Physiol Mol Biol Plants, 2017, 23(4):817-825. doi: 10.1007/s12298-017-0465-4

\section{Figures}

A 100

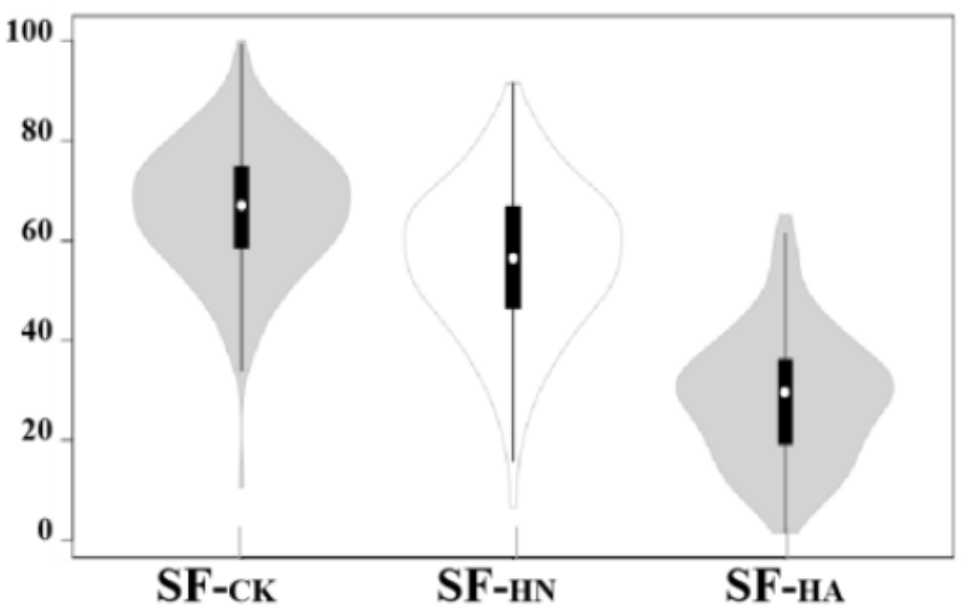

\section{C}

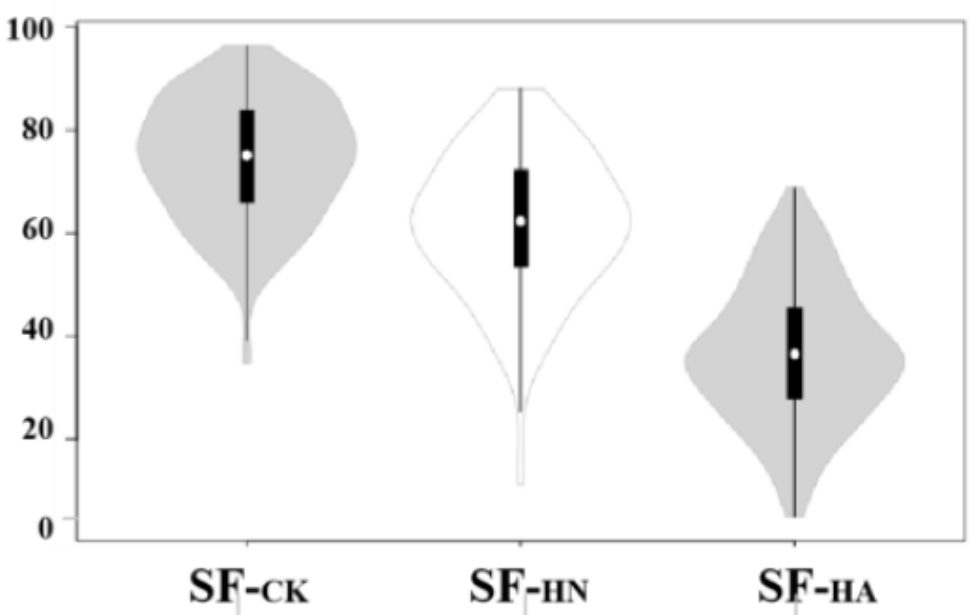

B

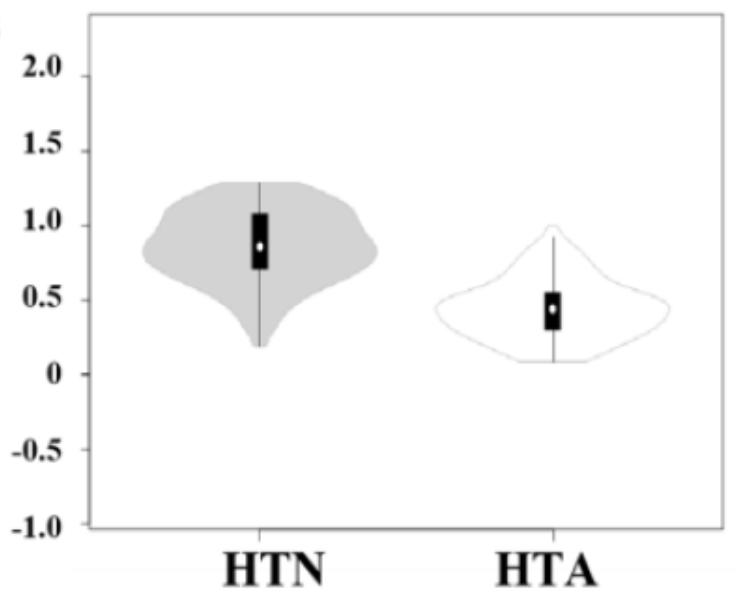

D

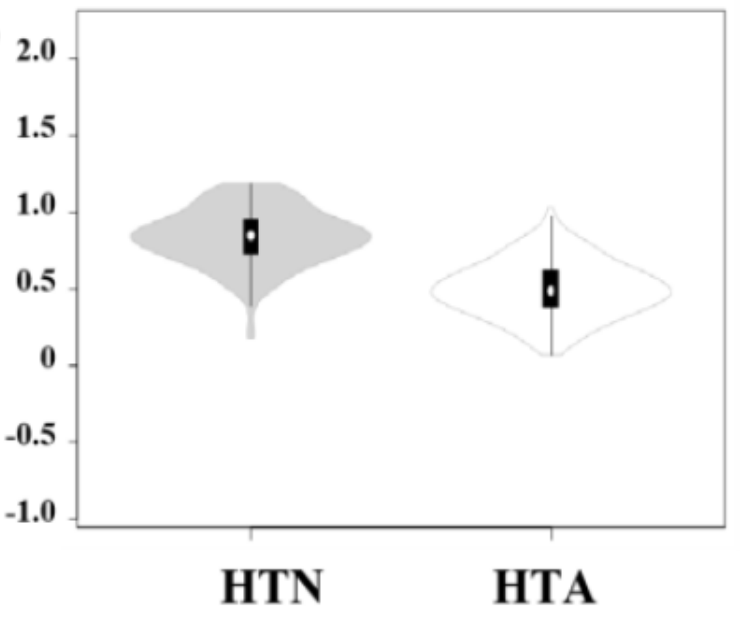

\section{Figure 1}

Violin plots of frequency distributions for SF and HT under different environments in the RIL populations. Note: A and B represent for SF and HT under the control, natural and artificial high temperature environments in 2019; C and D represent for SF and HT under the control, natural and artificial high temperature environments in 2020 , respectively. 

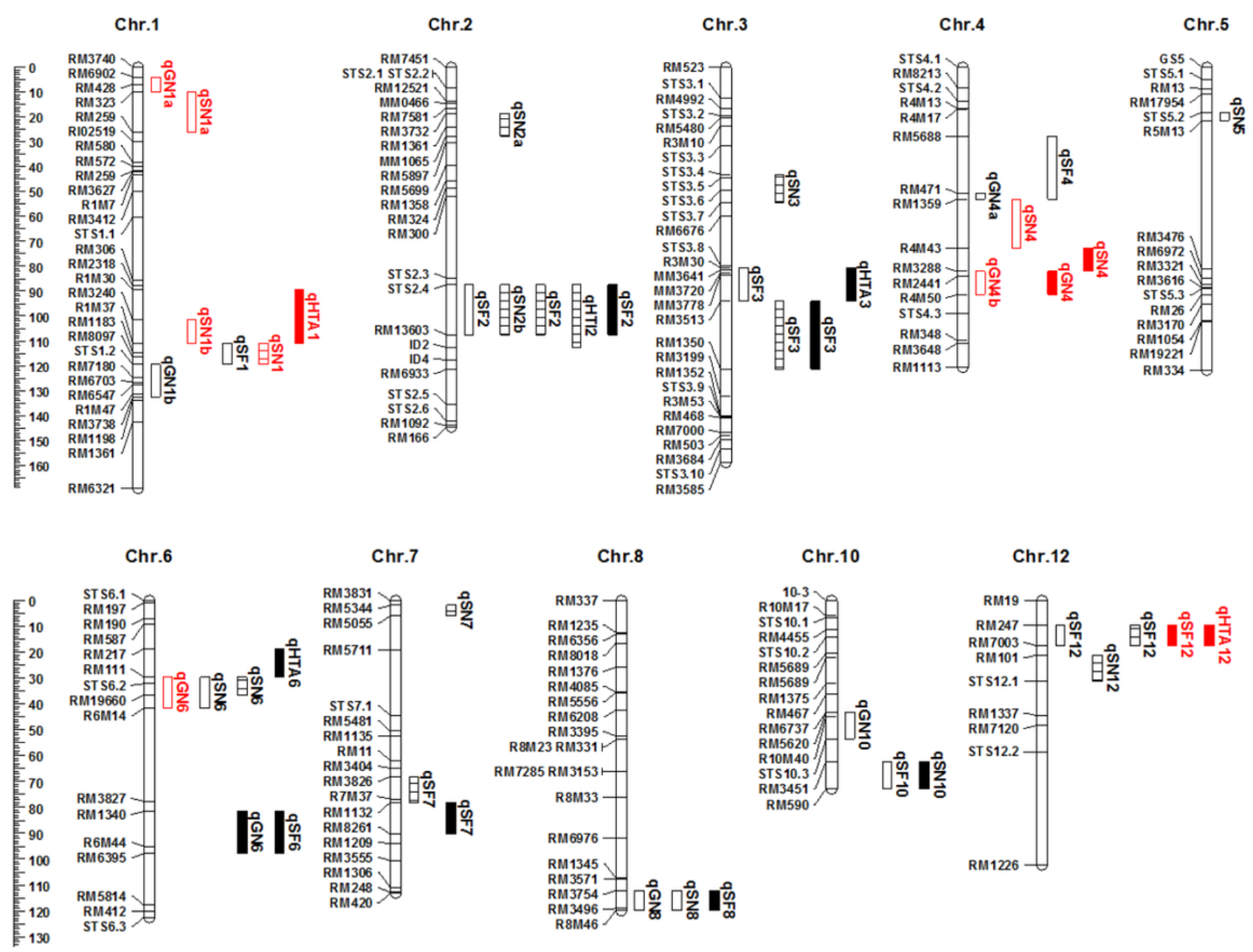

Figure 2. Location of QTL detected for heat tolerance-related traits on the RILs populations genetic map

，目 and QTL were detected on control, natural and artificial high temperature treatments, the black and red color represent for QTLs detected in one and two year, respectively.

\section{Figure 2}

See image above for figure legend.
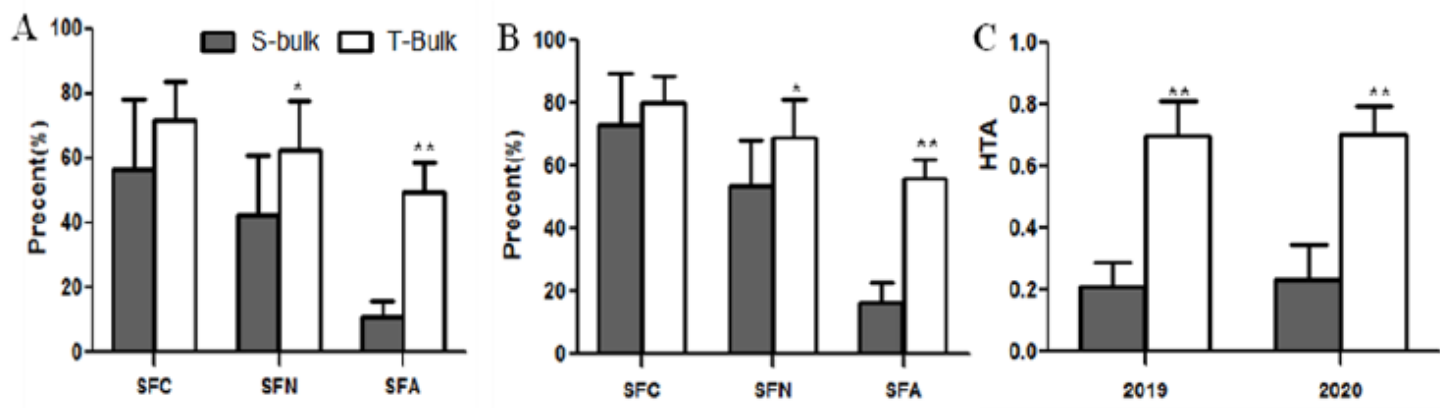

Figure 3

Comparative analysis of the SF-related traits between the HS-bulk and HT-bulk A and B represent SF under control, natural and artificial high temperature in 2019 and 2020, respectively; C represents HTA in 2019 and 2020. 
A
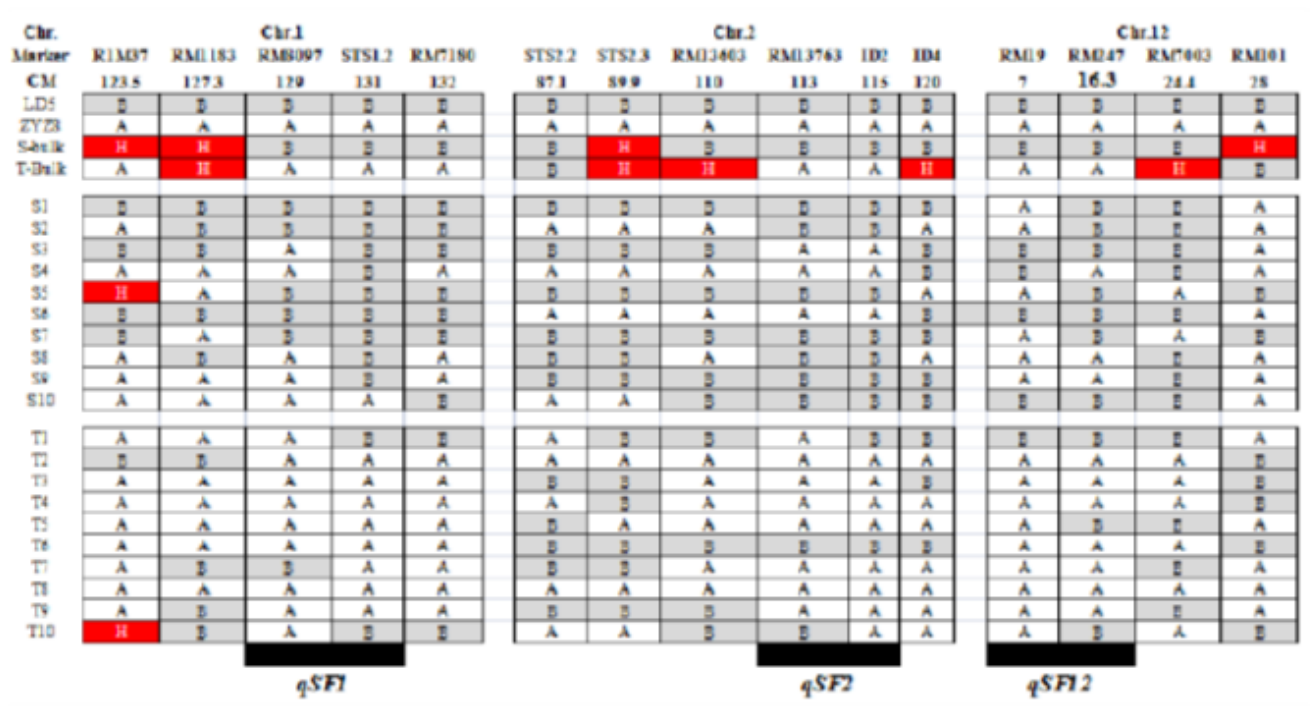

B

\begin{tabular}{|c|c|c|}
\multicolumn{1}{c}{ Chr.1 } & Chr.2 & Chr.12 \\
\hline- & - & - \\
\hline$q S F 1$ & - & - \\
\hline- & $q S F 2$ & - \\
\hline- & - & $q S F 12$ \\
\hline$q S F 1$ & $q S F 2$ & - \\
\hline$q S F 1$ & - & $q S F 12$ \\
\hline- & $q S F 2$ & $q S F 12$ \\
\hline$q S F 1$ & $q S F 2$ & $q S F 12$ \\
\hline
\end{tabular}

\begin{tabular}{cc}
\multicolumn{2}{c}{2019} \\
\hline SFA & HTA \\
8.77 & 0.16 \\
20.81 & 0.39 \\
18.20 & 0.25 \\
12.16 & 0.25 \\
47.77 & 0.65 \\
50.45 & 0.69 \\
65.05 & 0.74 \\
47.36 & 0.77
\end{tabular}

\begin{tabular}{ccc}
\multicolumn{2}{c}{2020} & \\
\cline { 1 - 2 } SFA & HTA & \\
$\mathbf{1 5 . 8 2}$ & $\mathbf{0 . 2 3}$ & $\mathbf{n}=6$ \\
$\mathbf{3 2 . 2 0}$ & $\mathbf{0 . 4 2}$ & $\mathbf{n}=4$ \\
$\mathbf{1 5 . 6 4}$ & $\mathbf{0 . 2 0}$ & $\mathbf{n}=2$ \\
$\mathbf{7 . 8 6}$ & $\mathbf{0 . 0 9}$ & $\mathbf{n}=1$ \\
$\mathbf{5 0 . 7 9}$ & $\mathbf{0 . 6 6}$ & $\mathbf{n}=\mathbf{3}$ \\
$\mathbf{5 4 . 9 3}$ & $\mathbf{0 . 7 5}$ & $\mathbf{n}=\mathbf{3}$ \\
$\mathbf{5 7 . 0 0}$ & $\mathbf{0 . 6 4}$ & $\mathbf{n}=2$ \\
$\mathbf{5 7 . 0 7}$ & $\mathbf{0 . 6 8}$ & $\mathbf{n}=4$
\end{tabular}

Figure 4

Bulked segregant analysis and three QTLs affected the SF in extremely performing lines 